\title{
Desenvolvimento do Pensamento Computacional: Um relato de atividade junto ao Ensino Médio, através do Estágio Supervisionado em Computação III
}

\author{
Lucas Tadeu Hinterholz ${ }^{1}$, Marcia Elena Kniphoff da Cruz ${ }^{1}$ \\ ${ }^{1}$ Licenciatura em Computação - Universidade de Santa Cruz do Sul (UNISC) \\ Av. Independência, 2293, Universitário - 96.815-900 - Santa Cruz do Sul - RS - Brasil \\ lhinterholz@gmail.com, mcruz@unisc.com
}

\begin{abstract}
The computational thinking encourages problem solving in all areas of knowledge, having origin in Computer Science. This paper reports a proposal based on incentive of computational thinking through principle of "Computer Science Unplugged". The study was conducted through the Supervised Internship in Computer III of the Bachelor's Degree in Computer Science from the University of Santa Cruz do Sul. All the activities were performed in a public school in the city of Santa Cruz do Sul/ RS with high school class and had as content database system fundamentals. We conclude that the progress of the students was very satisfactory and disciplines related to incentive of computational thinking must incorporate the formal curriculum of schools.
\end{abstract}

Resumo. O pensamento computacional incentiva a resolução de problemas em todas as áreas do conhecimento, tendo origem na Ciência da Computação. Este relato tem sua proposta baseada no incentivo ao pensamento computacional, com base no princípio da "Computação Desplugada". O trabalho foi realizado através do Estágio Supervisionado em Computação III, do curso de Licenciatura em Computação da Universidade de Santa Cruz do Sul. O estágio foi realizado em escola pública do município de Santa Cruz do Sul/RS com turma do Ensino Médio e abordou, como conteúdo, fundamentos de Banco de Dados. Conclui-se que o aproveitamento por parte dos alunos foi plenamente satisfatório e que disciplinas relativas ao incentivo do pensamento computacional devem integrar o currículo formal das escolas.

\section{Introdução}

Formar um professor dinâmico e preparado para as diversas situações no ambiente escolar são alguns dos desafios enfrentados por cursos de Licenciatura em Computação no país. Nas escolas, além de alunos pouco estimulados, os licenciados se confrontam com a resistência da inclusão da computação como parte do currículo.

Este artigo objetiva relatar as atividades de inserção de alguns conceitos básicos de Ciência da Computação no ensino médio através do estudo de Banco de Dados para o incentivo do pensamento computacional. As atividades são parte integrante do Estágio Supervisionado em Computação III do Curso de Licenciatura da Universidade de Santa Cruz do Sul, tendo sido realizadas por futuro professor de informática em escola estadual no município de Santa Cruz do Sul/RS. A proposta consistiu no ensino de fundamentos de Banco de Dados para introduzir a computação como ciência no 
currículo formal e teve propulsão pelos estudos realizados na referida disciplina. A iniciativa conseguiu incentivar o desenvolvimento do pensamento computacional, comprovadamente necessário para o refinamento da capacidade de pensar de forma lógica e abstrata (Blinkstein. 2008).

A importância do tema está pautada na necessidade de armazenamento da informação. O planejamento das atividades do estagiário tomou como base a proposta do livro Computer Science Unplugged (2007) que propõe o ensino de computação sem intermédio de um computador. As aulas ministradas foram planejadas sobre conteúdos da área de Banco de Dados e oportunizaram uma abordagem científica sobre computação.

A segunda seção do artigo apresenta o Referencial Teórico que embasou o trabalho durante as aulas compartilhadas com professor titular. Ainda, aborda o conceito e importância de introduzir o pensamento computacional e define o conceito de Banco de Dados na sua aplicação e justificativa de escolha. A terceira seção contempla a metodologia de trabalho do estudante de Licenciatura em Computação em sala de aula baseada no conceito de "Computação Desplugada". Serão apresentados os conteúdos abordados associados ao contexto e levando em conta a aplicação prática. As seções quatro e cinco apresentam os resultados obtidos com a proposta de trabalho, as discussões de fatores importantes que contribuíram para o bom aproveitamento dos alunos, seguida da conclusão.

\section{Referencial teórico}

Esta seção apresenta o referencial teórico para as atividades que foram desenvolvidas em sala de aula. A revisão literária é importante para que se possa traçar uma linha de trabalho concisa e, através dela, também foi possível a articulação de teoria e prática.

\subsection{Contexto escolar e legislação}

A função em essência da escola é a formação para a vida e para o mundo do trabalho. Segundo Gramsci (2001), houve uma época em que a escola treinava pessoas unicamente para suprir a necessidade de mão de obra, porém, baseada nas técnicas e ideologias que atendiam aos interesses da indústria. De fato, para muitos alunos, o Ensino Médio representa o último estágio antes da inserção no mercado de trabalho. Além disso, consta do Plano Curricular Nacional (PCN) o dever da escola em assegurar meios de progresso no trabalho através de uma educação cidadã. Baseado neste ideal, o Estágio Supervisionado em Computação III do curso de Licenciatura em Computação da Universidade de Santa Cruz do Sul planeja as atividades dos licenciandos integrados as escolas, em atendimento à instrução para o trabalho e às necessidades de formação docente.

Um dos marcos da educação no Brasil é a Lei de Diretrizes e Bases (LDB) de 1996 que institui a informática - este é o termo utilizado, embora pudesse ser Ciência da Computação - como instrumento complementar de estudos e de suporte interdisciplinar. Apesar de não estar estabelecida a obrigatoriedade de ser componente do currículo formal, este reconhecimento é uma conquista para a educação brasileira. Além disso, o Governo Federal viabiliza, por meio de subsídios, a criação de laboratórios de informática nas escolas públicas de todo país.

Embora exista esforço por parte das autoridades, uma análise preliminar da base de dados do censo escolar de 2011 realizado por um grupo de pesquisa da Bahia revelou 
a realidade da infraestrutura das escolas no Brasil. Somente $0,6 \%$ das escolas de ensino básico possuíam infraestrutura considerada ideal para ensino e 44\% tinham estrutura elementar (Santos et al. 2014). Levando em consideração que o censo avaliou a infraestrutura como um todo, pode-se pressupor que os laboratórios de informática também não atingem o que seria o ideal, em todos os casos.

Os recursos de que o professor dispõe em sala de aula podem influenciar o aproveitamento das atividades que ele propõe. Nesse sentido, cabe o discernimento de que muitas vez um insucesso de uma metodologia pode estar associado à infraestrutura ou a capacidade do professor de articular-se de acordo com o que está a disposição dele. Nesta perspectiva, Tim Bell em seu livro Computer Science Unplugged, sugere dezenas de atividades já validadas para ensinar Ciência da Computação para crianças. No entanto, o conceito de "Computação Desplugada" que o autor descreve pode ser facilmente aplicado para diferentes turmas, inclusive do Ensino Médio. Bell (2007) aponta alguns materiais básicos para as aulas. Entre eles estão quadro, caneta, papel, lápis, tesoura. Ou seja, recursos disponíveis em qualquer ambiente escolar. Esta proposta de trabalho pode facilmente ser adaptada mesmo em uma escola que não disponha de laboratório de informática, criando novas possibilidades aos alunos e professores.

\subsection{O Licenciado em computação e os Estágios Supervisionados}

Um professor de computação inserido no ambiente escolar deve proporcionar aos alunos um ambiente oportuno ao desenvolvimento da capacidade de pensar de forma abstrata, através de conteúdos e metodologias adequadas fazendo com que problemas complexos desfechem em soluções simples. O profissional habilitado para esta função é o Licenciado em Computação que estuda Ciência da Computação. A Licenciatura em Computação visa formar professores para o ensino de computação e informática nas escolas da Educação Básica em todas as suas modalidades e níveis de ensino. O curso visa atender à necessidade imediata de informatização e de avanços dessa área nos diversos setores da sociedade.

A carga horária de Estágio contempla a legislação de formação de professores que compreende 400 horas divididas, no referido curso entre quarto disciplinas de estágio, as quais o Estágio Supervisionado I e IV destinam-se ao Ensino Fundamental e Estágio Supervisionado II e III ao Ensino Médio.

Blinksetin (2008) define que o pensamento computacional não é saber navegar na internet ou enviar um email mas sim utilizar a tecnologia para fortalecer o poder de cognição. Ou seja, pressupõe o uso de computadores para aumentar a produtividade humana e traduz-se na necessidade de fazer os alunos pensarem e resolverem problemas como um computador. Reiterando, não implica saber utilizar um aplicativo como um editor de texto, mas tirar proveito do uso da tecnologia de forma geral.

A integração deste ensino específico na escola ainda encontra dificuldades principalmente quando se trata de infraestrutura de hardware e acesso a internet para pesquisas avançadas. Segundo Bell (2007), o ensino de Ciência da Computação sem necessariamente utilizar computadores viabiliza atividades que fomentem o pensamento lógico e computacional em quaisquer cenários. Escolas com localização de difícil acesso e pouca infraestrutura, por exemplo, ganham a oportunidade de receber este ensino mesmo sem dispor de um laboratório de informática. 
Um trabalho correlato demonstra o sucesso da inserção do pensamento computacional na educação básica. Um grupo de alunos e professores da UFPB demonstrou a possibilidade, por exemplo, da introdução de conceitos complexos de representação de informação (Scaico et al. 2013). Através da proposta do livro Computer Science Unplugged, estudantes de Estágio Supervisionado em Computação realizaram atividades recreativas de conversão de números binários com turmas de ensino fundamental dentro da sala de aula convencional e utilizando escrita em papel e no quadro branco. Conseguir ensinar ciência computacional para uma criança ou adolescente sem intervenção de um computador representa uma quebra de paradigma, tendo em vista que o ensino para estes níveis se apoia em softwares educacionais, em geral, utilizados de forma limitada ou inadequada.

\subsection{Banco de Dados: conceito e aplicação}

Segundo Heuser (1998) um Banco de Dados é definido por uma coleção de dados que se interligam uns aos outros em uma cadeia de relacionamentos. Tal modelo de organização se mantém geralmente centralizado e objetiva atender as necessidades de um grupo de pessoas que dependem destas informações. Já o acesso e gerenciamento destas informações agrupadas é viabilizada pelo Sistema de Gerenciamento de Banco de Dados - SGBD -, que também é responsável pela integridade e disponibilidade das mesmas. Ou seja, o SGBD deve garantir o armazenamento da informação sem qualquer alteração que não seja pela intervenção do usuário e mantê-la disponível a qualquer momento.

Um sistema de Banco de Dados é necessário em muitas situações e contextos como, por exemplo, os repositórios de artigos que representam a segurança do conhecimento científico de uma região, país ou associação. É essencial, inclusive, para o registro e manutenção de um determinado idioma. No Brasil, a PUC/SP é responsável pela manutenção de uma base de dados que armazena 233 milhões de palavras do idioma Português Brasileiro escrito e falado (Simões e Melo. 2008). Daí, é que se pode traçar uma relação do tema com a sua relevância para o ensino ainda na escola.

Sob a perspectiva de Heuser (1998), o ensino de Banco de Dados pode ser divido em dois grandes eixos: modelagem e SGBD. Visto a complexidade de abordagem de um SGBD em todas as suas especificações e particularidades, neste trabalho o ensino introdutório ao tema restringiu-se à modelagem, que é propriamente por onde tudo se inicia.

\section{Metodologia}

A metodologia de trabalho foi desenvolvida durante a disciplina de Estágio Supervisionado em Computação III e consistiu em ministrar aulas compartilhadas em sala de aula convencional, utilizando-se do laboratório de informática somente no encontro final. O estágio ocorreu na Escola Estadual Nossa Senhora do Rosário, localizada no bairro Universitário do município de Santa Cruz do Sul/RS. O currículo escolar da instituição contempla a informática somente como apoio pedagógico, sem que seja componente obrigatório.

Inicialmente houve o acompanhamento de algumas aulas no laboratório de informática para avaliar aspectos da turma de $2^{\circ}$ ano do Ensino Médio. Posteriormente, foi apresentado ao professor titular e à direção da escola a proposta de trabalho focada no incentivo ao pensamento computacional e as suas contribuições. A metodologia utilizada em sala de aula seguiu sugestões de atividades do livro Computer Science 
Unplugged (2007) para estimular a cognição e raciocínio lógico, e a sua eficácia foi comprovada por avaliação contínua.

As aulas de computação com a introdução a Banco de Dados ocorreram ao longo de quatro semanas com turma de $2^{\circ}$ ano de Ensino Médio da Escola Nossa Senhora do Rosário, tempo suficiente para que pudessem abstrair os conceitos e contextualizar as mais diversas aplicações. Os encontros aconteceram quase que na totalidade em sala de aula convencional com quadro-negro e somente ao fim do estágio é que o laboratório de informática fui utilizado. Isso representa uma contradição a ideia de que só se aprende computação em frente a um computador. As atividades desenvolvidas em sala de aula no contexto de Banco de Dados articulam-se ao pensamento computacional quando requerem que os alunos avaliem relacionamentos lógicos fundamentais para a integridade dos dados. Isto exige uma ação reflexiva para a resolução deste problema. Em um Banco de Dados, as relações entre chaves primárias e secundárias é que definem a agilidade dos processos.

Atualmente, dispõe-se de uma vasta gama de Sistemas de Gerenciamento de Banco de Dados - SGBD, cada um deles com uma proposta e linguagem específicas como, por exemplo, MySql, Postgres, Oracle 11g e Mongo DB. Para este trabalho não foi introduzida a programação de Banco de Dados através de linhas de código, mas sim, o seu conceito genérico de aplicação. Os softwares utilizados foram o Access e o Base, ambos em português e de fácil manipulação pelo usuário.

Na primeira aula de Banco de Dados foram abordados conceitos teóricos básicos como tabela, dado, elemento de dado, SGBD e Database Adminsitrator, ou, cientista de dados. O simples fato de conhecer estas definições básicas já são um adendo para o currículo dos alunos que eventualmente concorram à vagas em empresas de médio e grande porte que fazem uso de um Banco de Dados. A Figura 1 apresenta o estudante de Licenciatura em Computação na primeira aula utilizando do método expositivo dialógico na explicação dos conceitos básicos de Banco de Dados.

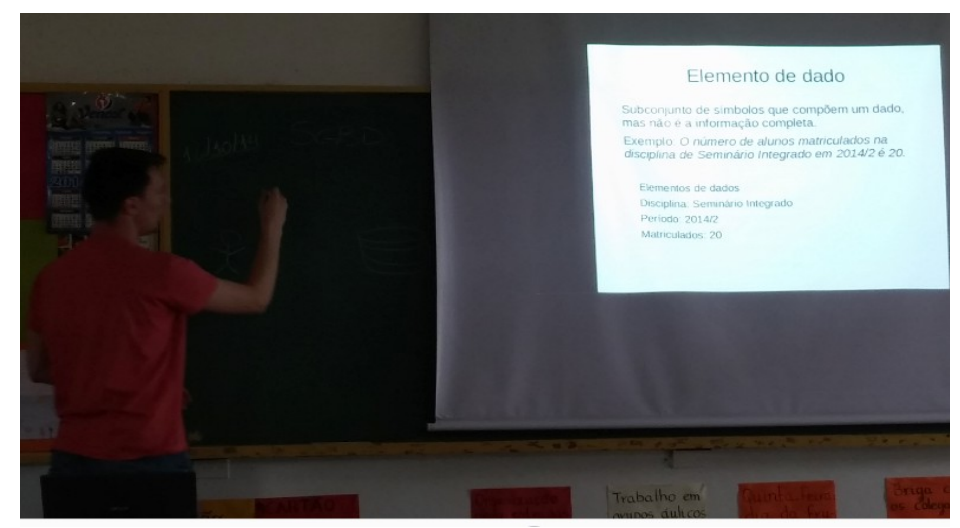

Figura 1 - Registro da primeira aula de Banco de Dados em sala de aula convencional

Foi necessária uma maneira de introduzir o tema com exemplos do cotidiano dos alunos para contextualização. Isso porque, eles não tinham conhecimento prévio do assunto. Explicando a aplicação em comércio, bancos e lojas os alunos puderam compreender de forma prática. Também foi utilizado como exemplo o Facebook, que constitui-se de um Banco de Dados muito robusto implícito à sua interface gráfica. Exemplos familiares aos alunos facilitam a abstração daquilo que poderia não fazer sentido se não estivesse tão próximo. É fundamental que o professor conheça a 
realidade do aluno, o que ele está fazendo no mundo virtual e quais as tendências. Segundo Nosella (1992), quem deseja produzir algum conhecimento científico precisa estar atento ao dia a dia e prestando atenção nas particularidades significantes.

Um aspecto da metodologia utilizada em aula é o caráter provocativo. Os alunos foram desafiados a sair da zona de conforto, imaginando aplicações e modelando tabelas com os devidos relacionamentos. Sob esta perspectiva, foi proposta uma atividade prático teórica de fixação. Em um primeiro momento, foi modelado no quadro tabelas e relacionamentos de um Banco de Dados com o cenário de um supermercado. Foram discutidos os possíveis dados e atribuídos às linhas e colunas das tabelas. Ao final, haviam sido criadas as tabelas Mercado, Produto, Gênero, Fornecedor, Funcionário e Função, com seus respectivos atributos. Para contextualizar, os alunos precisaram compreender o seguinte. A organização do estoque de um estabelecimento comercial através de um sistema e um Banco de Dados aumenta sua produtividade. De certa forma, para que isso seja possível, é necessário um modelo computacional. Quando se digitaliza um setor ou um processo já se está praticando o pensamento computacional. Segundo Blinkstein (2008), o pensamento computacional inicia identificando em quais tarefas cognitivas um computador pode nos substituir.

A Figura 2 ilustra a organização criada e o relacionamento das tabelas pelas chaves primárias (PK) e chaves estrangeiras (FK). Por exemplo, o produto de código 1 é "banana", sua unidade de medida é em kg, o preço por kg é 3,32 - aqui sem definição de moeda -, o código do fornecedor é 12 - conforme a Tabela Fornecedores - e o código do gênero está indefinido. Analisando a Tabela Gênero, o produto "banana" se enquadra no gênero "alimentos", representado pelo código 1. Ou seja, o campo cod_genero na Tabela Produtos é referenciado pelo código 1 da Tabela Gênero. Isso implica dizer que o atributo cod_genero é chave estrangeira na Tabela Produtos e chave primária na Tabela Gênero. Esta assimilação é essencial para que o aluno possa compreender a dinâmica de um Banco de Dados.

\begin{tabular}{|c|c|c|c|c|c|}
\hline \multicolumn{6}{|c|}{ TABELA PRODUTOS } \\
\hline $\operatorname{cod}$ & nome_produto & medida & preco_un & cod_fornecedor & cod_genero \\
\hline 1 & banana & $\mathrm{kg}$ & 3.32 & 12 & \\
\hline 2 & azeite & un & 1.23 & 54 & \\
\hline 3 & leite & 1 & 0.90 & 22 & \\
\hline 4 & sabonete & un & 1.5 & 2 & \\
\hline 5 & carne & $\mathrm{kg}$ & 10.00 & 22 & \\
\hline \multicolumn{3}{|c|}{ TABELA GÊNERO } & & & \\
\hline $\operatorname{cod}$ & genero & setor & & & \\
\hline 1 & alimentos & 1 & & & \\
\hline 2 & higiene & 2 & & & \\
\hline 3 & saude & 3 & & & \\
\hline 4 & ferramentas & 4 & & & \\
\hline
\end{tabular}

Figura 2- Representação de duas tabelas que se relacionam por chave primária (PK) e chave estrangeira (FK).

Os alunos ao mesmo tempo propunham elementos e se revezavam no quadro desenhando e escrevendo. Todos contribuíram de alguma forma fazendo suposições e questionamentos acerca do que estavam produzindo. O estagiário somente induzia para uma solução ou caminho quando percebia que os alunos não conseguiam chegar a um consenso na organização das tabelas. Caso contrário, lhes dava autonomia na composição da tabela conforme desejassem. 
Com o revezamento dos alunos, os papéis no processo de aprendizagem eram constantemente invertidos. Aquele que estivesse escrevendo no quadro sempre assumia uma postura de liderança em relação aos demais, o que fazia com que todos quisessem experimentar. Na Figura 3 é possível ver um dos alunos desenhando e escrevendo no quadro de acordo com as informações vindas dos colegas.

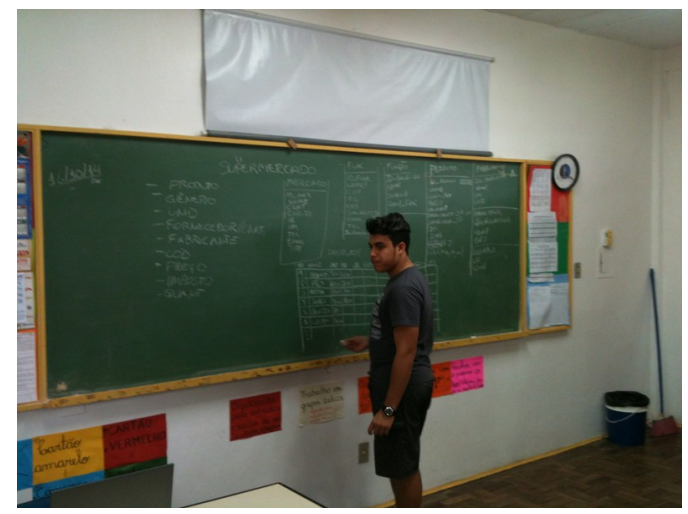

Figura 3 - Aluno de $2^{\circ}$ ano do Ensino Médio desenhando tabelas com auxílio dos colegas.

Outro desafio no sentido de fazer com que os alunos refletissem seguiu-se por nova atividade prática, desta vez subdivididos em grupos de três a cinco integrantes. Os grupos foram desafiados a propor um cenário a seu gosto e modelar o banco juntamente com os possíveis dados. Entretanto, a modelagem deveria ser feita em papel. Os cenários foram variados: locadora de vídeo, escola, time de futebol e lojas.

A imposição de um ritmo de ação mais ativa dos alunos em aula revela o interesse em um ensino que busca formar, e não somente informar. Estamos considerando um ensino preparador para o mundo do trabalho - ou para a universidade, que também vai preparar - e este conceito converge para o pensamento Gramsciniano que considera a instrução (conteúdo) parte da educação, mas credita à formação (método) um papel essencial (Nosella. 1992).

Das quatro aulas introdutórias a Banco de Dados somente na última foram utilizados computadores. Com as suas tabelas desenhadas no caderno, a turma se dirigiu até o laboratório de informática da escola para que fosse feita a transposição dos dados para o SGBD. Os mesmos grupos que fizeram as tabelas no caderno se reagruparam dentro do laboratório e tinham a tarefa de digitalizar todas as tabelas e dados respeitando os relacionamentos de chave primária e chave estrangeira que haviam definido. A figura 4 mostra um grupo de alunos digitando os dados em uma tabela, e também a tabela finalizada no software designado.
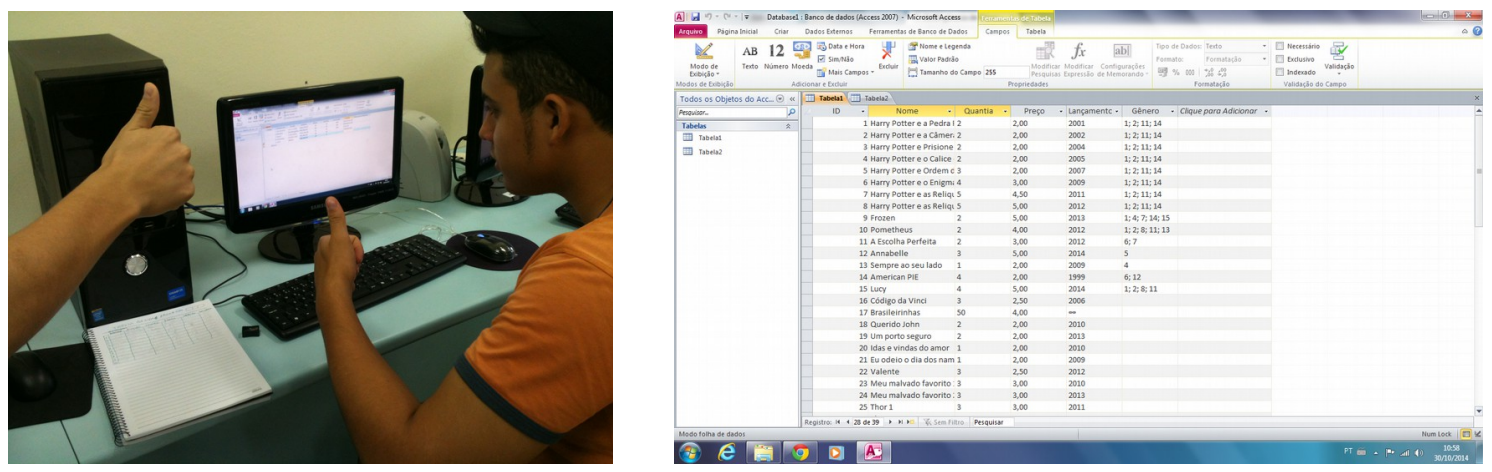
Figura 4 - Alunos transpondo as tabelas do caderno para o software especificado e o resultado de um Banco de Dados de uma locadora de vídeos.

Com base no relato das atividades do Estágio Supervisionado em Computação III é importante discutir as questões: Quais são os resultados do ensino de Ciência da Computação em uma sala de aula convencional? Qual a receptividade dos alunos em relação à computação como disciplina? Quais foram as contribuições para o incentivo ao pensamento computacional?

\section{Resultados e Discussões}

Imaginar cenários, desenhar tabelas, apontar relacionamentos e comparar dados são ações que estimulam o cérebro a trabalhar de forma sistêmica, ordenando o pensamento como em uma sequência de passos para chegar a uma resolução (Nunes. 2011). E de acordo com a literatura, é também assim que o um sistema computacional se comporta. Fazer com que alunos de Ensino Médio pensem sob a ótica de um computador estimula o pensamento computacional. Receber uma informação, analisar, imaginar e aplicar uma resolução. É desta forma que o aluno se condiciona a resolver problemas.

Segundo Nunes (2011), o pensamento computacional é a base da Ciência da Computação e pode ser aplicada a qualquer outra área do conhecimento pois em todas elas existe a necessidade do raciocínio lógico para calcular ou escrever um texto. A importância de iniciar o processo já na escola baseia-se no fato de ser um momento de formação do ser. É conveniente aprender estes conceitos antes de ingressar no mercado de trabalho.

Quanto à análise do feedback dos alunos, foi possível extrair resultados muito expressivos. No início das atividades, por exemplo, muitos se mostraram dispersos. Aparentemente, para eles seria somente mais uma aula na sala de aula comum. Ou, esperavam sentar em frente ao computador receber uma série de informações. No entanto, quando conheceram a proposta mostraram um interesse incomum. Os alunos não entendiam como seria possível aprender o que era proposto longe do laboratório de informática e isso os instigou. Quando questionados, os alunos afirmaram não saber que era possível estudar computação utilizando apenas cadernos, lápis e sua própria imaginação. Logo na primeira atividade junto ao quadro, mesmo aqueles que anteriormente se mostraram mais dispersos, passaram a se interessar e participar de forma mais ativa. Neste momento já havia sido despertado o interesse.

Nos momentos em que precisaram escrever em papel, mais um paradigma se quebrava. Aprender Ciência da Computação modelando tabelas no caderno gerou questionamentos e foi isso que se esperava. Para Almeida et al. (2000), toda formação acontece na prática e portanto não seria possível aprender Banco de Dados sem planejar, desenhar, apagar, reescrever e discutir os dados em papel. A tarefa de desenhar tabelas representou o planejamento do projeto antes de qualquer execução no computador. Como puderam escolher os cenários, o fizeram de acordo com suas preferências em comum com os demais colegas de grupo. Futebol, moda, comércio e música foram algumas das seleções. Os alunos tomaram decisões coletivamente e puderam ser autônomos do seu próprio processo educativo.

Mais do que o pensamento computacional, o processo criativo dos alunos foi ativado. Acompanhando os grupos, foi possível a análise de que o que estava ocorrendo lhes interessava. Discutiam os atributos das tabelas como num jogo de estratégia. 
Definiam em quais situações seria necessária uma tabela intermediária para facilitar algumas interações e quais deveriam ser as chaves primárias e estrangeiras. Muitas vezes esqueciam de algum ou outro conceito, mas estavam trabalhando.

Com tabelas prontas e já ao final das atividades no laboratório de informática, os resultados foram ainda mais animadores. Ainda que tenham tido bom aproveitamento em sala de aula, os alunos estavam ansiosos para dar mais sentido aos seus cenários. Analisando a turma enquanto digitavam, foi possível notar satisfação naquilo que faziam. Segundo Hengemühle (2005), quando um modelo ou uma proposta de ensino é capaz de motivar o aluno, ele se mostra muito mais interessado.

\section{Conclusão}

Este trabalho apresentou o relato das atividades desenvolvidas com alunos de $2^{\circ}$ ano do Ensino Médio para o incentivo do pensamento computacional através do Estágio Supervisionado em Computação III. O conteúdo abordado foi Banco de Dados e teve a intenção de articular este conhecimento com o caráter científico da Ciência da Computação. Através de atividades teórico-práticas os alunos foram desafiados a condicionar a sua cognição e utilizar muito o pensamento lógico.

É possível afirmar que a inclusão da Ciência da Computação como disciplina curricular representa ganhos significativos. Segundo Nunes (2011), as universidades não formam profissionais de computação na mesma proporção da demanda existente. Sendo assim, torná-la parte do currículo formal escolar aumentaria as chances de novos graduandos para cursos de Ciência, Engenharia e Licenciatura em Computação. Ainda segundo o autor, o desenvolvimento do pensamento computacional no aluno tem reflexos até mesmo na economia do país. As novas tecnologias que são desenvolvidas movimentam de forma significativa vários setores da indústria.

Ao final das atividades propostas foi possível alcançar os resultados esperados. O trabalho afetou o modo de pensar dos alunos e os estimulou a explorar mais sua capacidade cognitiva. Foi um passo importante para um esforço ainda em fase inicial de impulsionar o pensamento computacional e a introdução da computação como componente curricular. Diversas constatações foram possíveis. A mais significativa - e interesse principal - é que os alunos corresponderam às expectativas, comprovando o sucesso da proposta. No diagnóstico inicial, poucos alunos podiam ser considerados acima da média e, mesmo assim, quase que a totalidade da turma participou integralmente das tarefas. Desde a contextualização dos conceitos até a planificação dos dados e sua transposição no computador, os alunos tiveram excelente rendimento.

Estudos de casos recentes - e a própria experiência deste trabalho - revelam que este processo não tem crescido exponencialmente. Em Minas Gerais, o levantamento de dados de um projeto de inclusão de novas tecnologias na escola que já dura quase uma década, observou que $40 \%$ dos laboratórios implementados no início do projeto estão fechados ou foram revertidos em salas de aula. Segundo Vieira (2013), autora do estudo, isso representa um retrocesso no uso de tecnologias para o ensino e se justifica pela falta de recursos para manutenção dos ambientes naquele estado. Ou seja, embora existam subsídios, nem sempre eles são suficientes. Sob esta perspectiva, é que se entende a necessidade de explorar mais a "Computação Desplugada", de modo que este relato sirva de encorajamento a outros professores. 
É expectativa dos autores que este pequeno contributo motive professores e profissionais das áreas ligadas à tecnologia a continuarem buscando o espaço da computação enquanto ciência que deve integrar os currículos escolares.

\section{Referências}

Almeida, Cristina C. and Carvalho, Luciano P. (2012) "A formação de professores no curso de Licenciatura em Computação: um relato das práticas educacionais de iniciação a docência”, In: XVII WIE, Brasil. SBC.

Bell, T., Whitten, I. And Fellows, M.. (2007) "Computer Science Unplugged", http://csunplugged.org/. Acesso em: 20/05/2015.

Blinkstein, Paulo. (2008) "O pensamento computacional e a reinvenção do computador", http://www.blikstein.com/paulo/documents/online/ol_pensamento_computacional.ht ml. Acesso em: 20/05/2015.

Brasil. (1996) "LDB - Lei de Diretrizes e Bases", http://www.planalto.gov.br/ccivil 03/leis/L9394.html. Acesso em: 15/05/2015.

Brasil. (2008) "PCN - Parâmetros Curriculares Nacionais", http://portal.mec.gov.br/seb/arquivos/pdf/livro01.pdf. Acesso em: 15/05/2015.

Gramsci, Antônio. (2001) "Cadernos do cárcere”, In Civilização Brasileira, Vol. 2, 2a Ed., Rio de Janeiro, Brasil.

Heuser, Carlos. (1998) "Projeto de Banco de Dados", In: Editora Sagra Luzzato, 4" edição, Porto Alegre.

Nosella, Paolo. (1992) “A escola de Gramsci”, In Artes Médicas: Porto Alegre.

Nunes, Daltro. (2011) "Ciência da Computação na Educação Básica", http://www.adufrgs.org.br/artigos/ciencia-da-computacao-na-educacao-basica/. Acesso em: 27/05/2015.

Santos, M. S. et al. (2014). “Análise das infraestruturas de censo escolar 2011: uma proposta da disciplina de Tópicos em Banco de Dados”, In: XXV SBIE, Brasil. SBC.

Scaico, Pasqueline D. et al. (2012). "Um relato da experiências de estagiários de Licenciatura em Computação com o ensino de computação para crianças", In: RENOTE - Novas Tecnologias na Educação, Vol. 10, N. 3, 2012, Porto Alegre.

Scaico, Pasqueline et al. (2013) "Relato da utilização de uma metodologia de trabalho para o ensino de Ciência da Computação no Ensino Médio", In: XVIII WIE, Brasil. SBC.

Simões, Darcília and Melo, Eliana M. (2008) “A relevância dos Bancos de Dados para o ensino da Língua Portuguesa”, In Revista Prolíngua, Vol. 2, N. 2, p. 12-24, Brasil.

Vieira, Márcia de F. (2013). "8 anos de informática na educação nas escolas públicas”, In: IX WIE, Brasil. SBC. 